“C 2017 IEEE. Personal use of this material is permitted. Permission from IEEE must be obtained for all other uses, in any current or future media, including reprinting/republishing this material for advertising or promotional purposes, creating new collective works, for resale or redistribution to servers or lists, or reuse of any copyrighted component of this work in other works." 


\section{Analysis of DFIG Machine with Rotor-Wound Faults}

\author{
Ahmad A. Salah and Youguang Guo \\ Faculty of Engineering \& IT \\ University of Technology Sydney \\ Sydney, NSW 2007, Australia \\ Ahmad.a.salah@student.uts.edu.au \\ Youguang.Guo-1@uts.edu.au
}

\author{
David G. Dorrell \\ Discipline of Electrical, Electronic and Computer \\ Engineering \\ University of KwaZulu-Natal \\ Durban 4041, South Africa \\ Dorrelld@ukzn.ac.za
}

\begin{abstract}
The round rotor induction machine (WRIM) can be described as a doubly fed induction generator (DFIG) when driven above the synchronous speed, and the stator and rotor windings are connected to the whole system. The work in this paper develops a relatively simple powerful model that can accurately analysis the behavior of DFIG with rotor-wound faults. The model is based upon the calculation of the stator current components, which are needed to the build impedance matrix. This method is used here to detect the rotor asymmetry fault on a four-pole wound rotor. Measured torque, current, and power loss results are compared with computer predictions for the machine with a rotor connected to symmetrical or asymmetrical external resistance. An equivalent circuit for a wound rotor induction machine, which includes external resistances, is derived. This is essential for building a better understanding of the fault components computed from the matrix. Simulation and experimental results evidence the validity of the suggested method, leading to an improved condition monitoring system for diagnosing faults in WRIMs.
\end{abstract}

Keywords-Doubly fed induction generator (DFIG); impedance matrix; sfator windings; wound rotor induction machine (WRIM).

\section{INTRODUCTION}

The induction machine is reliable and widely used in industrial plants. Recently wound rotor induction machines (WRIM) have been used for modern wind power generation systems. WRIMs can produce a high energy output with a low rating of the power converter coupled to the rotor side. Using effective condition monitoring for scheduling maintenance can ensure that catastrophic failures do not occur in the system. According to [1][2], condition monitoring is becoming an increasingly important of a renewable energy system, especially for the electrical machinery. Different methods for fault identification have been developed and used effectively to detect the machine faults at different stages using machine variables, such as current, voltage, speed, torque, noise and vibrations [1][2]. In most cases, faults produce one or more indicative signs, such as increased losses, excessive heating, torque pulsation, and unbalanced air-gap voltages and line currents. The faults were listed in [3], where $41 \%$ are bearing faults, $37 \%$ are stator faults, $10 \%$ are rotor faults and $12 \%$ are the other faults.

Many authors have published techniques for analyzing asymmetrical wound rotor machines using positive and negative sequence equivalent circuits for a machine with unbalanced impedance in the secondary circuit, e.g. [4]. Stator current monitoring is another popular method where signature current sidebands are monitored [5]. It was stated in [6] that the component at $(1-2 s) f_{m}$ (where $s$ represents the slip and $f_{m}$ is the supply frequency) in the current spectrum is a sign of this fault, and most of the further studies were based on the current signature analysis [7]. Additionally, vibration signal analysis has been widely used in the fault detection of induction machines. Faults create harmonics with different frequencies and power levels in the vibration signal. Consequently the vibration signal is first sensed via a vibration sensor mounted on the stator frame, and then its spectrum is calculated using a Fourier transform or a fast Fourier transform (FFT). Each method has its advantages and disadvantages. However, the main idea is that these methods can detect faults as they develop and prevent excessive damage and reduce unexpected shutdowns.

This paper develops a method for the steady-state analysis of a WRIM or DFIG capable of including rotor asymmetry. The proposed technique has been already investigated in [8] and [9], and here the rest of the experimental work and simulation results are presented and discussed. The main contribution of this work is the application of the proposed technique to the diagnosis and detection of rotor imbalances faults while the fault at an early stage of development.

Determining the currents flowing in the various stator and rotor windings is the first stage of evaluating the rotor symmetry or asymmetry. By using the coupling impedance method described in [8], this can be done. The machine analysis resolves the airgap flux into a harmonic series of traveling waves with different pole numbers rotating in either direction. These could be derived using the currents and the spatial positioning of the rotor and stator conductors that can be represented in the form of a harmonic Fourier series of surface current density. Finally, this produces an expression for the conductor density distribution in terms of a harmonic series and can be derived using complex Fourier analysis to account for the magnitude and positioning of conductors on the stator and rotor surfaces. The presented analysis will also derive such quantities as power and torque. The authors have put the derivation of the coupling and mutual impedances in [9] and the rest of the experimental work and simulation results are presented here. This technique was used successfully in [8] and [10] to study cage rotor machines with any number and distribution of bar and/or eccentricity faults. Previously, the 
impedance matrices were used to detect the cage rotor failure. Here, the impedance matrices will be developed to include wound rotor coils in the same way. However, the wound rotor machine runs at a much higher slip than the cage rotor machine using slip energy recovery systems. The faults in wound rotor machines can vary greatly from the cage-rotor equivalent [11] and they are substantially higher.

When a balanced positive-sequence supply voltage is applied to the stator windings, each individual winding produces a forward rotating field in the air gap which induces slip frequency electromagnetic forees (EMFs) in the rotor windings. These EMFs will create currents in the rotor windings which will produce an air gap magnetic field that contains a field component fundamentally distributed and rotating in the forward direction. It also contains a field component of equal amplitude but rotating backward with respect to the rotor. Both field components rotate at slip speed. In the healthy rotor case, these backwards rotating components would be canceled and produced a zero resultant. However, in the case of broken rotor bars or rotor winding faults, the backwards rotating components resultant is not zero. The backwards rotating field rotates at slip speed with respect to the rotor, and rotates forwards with respect to the stator with speed equal to $(1-2 s)$ times of the synchronous speed. This backwards rotating field, therefore, induces EMFs in the stator windings with a frequency equal to $(1-2 s) f_{m}$. This approach shows that twice slip frequency components of the stator current spectral analysis could be used to determine broken bars in a cage rotor induction motor [12]. It has to be stated that if symmetrical components are used for asymmetrical machines, the analysis must be done in a reference frame fixed to the asymmetrical side, because the frequencies of the positive and negative sequence components are equal only in this reference frame.

This paper is organized as follows: the impedance matrix is developed in the second section of the paper; this also shows the derivation of the torque and input power for induction machines. The third section demonstrates the steady-state equivalent circuit for a WRIM. Simulation and experimental work are reported in the fourth and fifth sections.

\section{BUILDING THE MATRIX}

The rotor of a WRIM has a group of three-phase windings that are similar to those on the stator although the rotor slot number will vary and so will the rotor coil tum number. The derivation will be straightforward because the rotor loop currents do not share any common paths down bars [9]. The main feature of the method is that any asymmetrical winding can be taken into account. Furthermore, the electromagnetic field in the airgap can be derived and the EMF resulted in any winding can be calculated, leading to expressions for the coupling impedances between the various windings. These can be expressed in the form of an impedance matrix. The matrix technique was utilized to study brushless doubly-fed induction and reluctance machines [13]. Moreover it has been applied for single phase and split-phase induction machines. It can be expanded to incorporate eccentricity faults and the condition monitoring of wound rotor machines [14]. The impedance matrix includes all impedances in [9] which are functions of the three-phase windings on the stator and rotor:

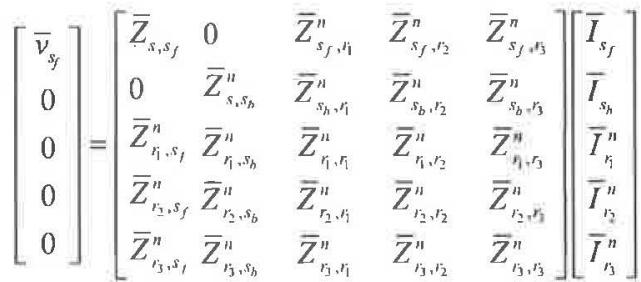

where $I_{s f}$ is the stator current, $I_{s h}$ the $(1-2 s)$ times mainsfrequency component, and $v_{s f}$ is the stator voltage. $Z_{s, s}, Z_{r, r}$ are the stator-stator coupling impedance and the rotor-rotor coupling impedance respectively. $Z_{s, r}, Z_{r, s}$ are the rotor-stator coupling impedance and the stator-rotor coupling impedance respectively. The rotor currents in (1) can be obtained from a knowledge of the applied voltages when the matrix is solved. The rotor voltage is supposed to be zero because the three phase rotor windings are short-circuited together. Superscript $(n)$ relates to stator harmonic, and $s_{1} r_{1}, r_{2}$, and $r_{3}$ correspond to stator and rotor phase windings of the machine respectively. Superscript $f, b$ correspond to forward and backward components.

In a healthy machine, there will be a magneto-motive force (MMF) wave on the rotor rotating at slip frequency $s f_{m}$ in the rotor coordinates. If there is asymmetry, then there will be a backward rotating MMF wave. It subsequently induces EMFs of frequency $(1-2 s) f_{n}$ in the stator windings. For that reason, it is necessary to add other components in the impedance matrix in order to accommodate the $(1-2 s) f_{m}$ current components. The analysis can be extended to include additional rotor voltages as would be found in a wound rotor soft starter (which is an old system) or a slip energy recovery scheme as found in the DFIG, which is used in many wind turbine generators. Therefore (1) can be further developed:

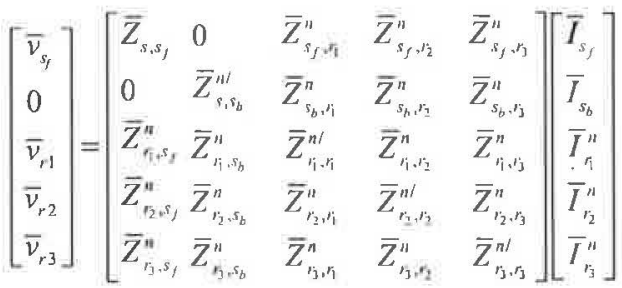

where

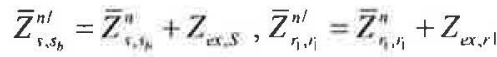

$$
\begin{aligned}
& \bar{Z}_{r_{2}, r_{2}}^{n \prime}=\bar{Z}_{r_{2}, r_{2}}^{n}+Z_{e x,+2} \text {, and } \bar{Z}_{r_{1}, r_{3}}^{n \prime}=\bar{Z}_{r_{1}, r_{3}}^{n}+Z_{e x,+3}
\end{aligned}
$$

The impedance matrix technique described in [9] is used to find the steady state equivalent circuit for the wound rotor. As mentioned early, all the derivations of the mutual and coupling impedance can be found in [9]. The impedance matrix can be simplified to

$$
\left[\begin{array}{c}
\bar{v}_{s} \\
0
\end{array}\right]=\left[\begin{array}{ll}
\bar{Z}_{s, s}^{\prime} & \bar{Z}_{s, r_{i}}^{\prime} \\
\bar{Z}_{n, s}^{\prime} & \bar{Z}_{r, r_{i}}^{\prime}
\end{array}\right]\left[\begin{array}{l}
\bar{I}_{s} \\
\bar{I}_{\eta_{\mathrm{i}}}
\end{array}\right]
$$

so we can obtain one equivalent circuit for the fundamental wave and single rotor phase when the rotor has balanced phases set. Hence the voltage is resolves to 


$$
\bar{v}_{s}=\left\{\bar{Z}_{s, s}^{1}+\frac{\bar{Z}_{s, j}^{1}\left(-\bar{Z}_{r_{1}, s}^{1}\right)}{\bar{Z}_{r, r}^{1}}\right\} \bar{I}_{s}
$$

\section{Power And TORQue Calculation}

The impedance matrix is first assembled and then adjusted to create the desired fault condition. The input power and reactive power may be calculated in a straightforward manner from the stator voltage and current since the stator supply has been assumed to be ideal as in (4):

$$
\vec{S}=3 \vec{V}_{i} \bar{I}_{i}^{*}
$$

The input power can be calculated from the positive sequence mains frequency current:

$$
P_{i}=\operatorname{Re}\left\{3 \bar{V}_{,} I^{*}\right\}
$$

The developed electromagnetic torque can be determined from the stator and rotor currents density distributions [10], which is generated as a result of the interaction between the stator and rotor fields. The stator and rotor currents densities are $j_{s}(y, t)$ and $j_{r}(y, t)$ respectively, including the forwards and backwards components. The torque is given by:

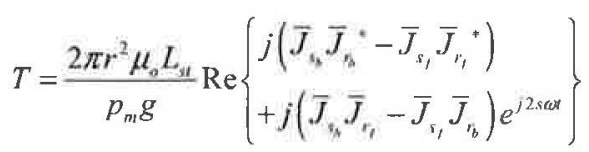

The fundamental pole-pair number of the machine is $p_{m}, L_{s t}$ is axial length of the stator, $g$ is airgap length, $\omega$ is the supply frequency in $\mathrm{rad} / \mathrm{s}, s$ is the slip, and $r$ is average airgap radius. The stator current density is:

$$
j_{s}(y, t)=\operatorname{Re} \sum_{n=-\infty}^{\infty} \bar{J}_{s j}^{n} e^{j\left(\left(x-n p_{m} k y\right)\right.}+\bar{J}_{s b}^{n} e^{j\left((2 s-1)\left(x+n p_{n}, k y\right)\right.}
$$

where $y$ is the spatial location of the stator slot and $k$ is the inverse of the average gap radius $(k=1 / r)$. For a balanced 3 phase current set, and using the identity $a=e^{(j 2 \pi / 3)}$, the forward component of MMF is

$$
\bar{J}_{s f}^{n}=\bar{N}_{s t}^{n}\left(1+a^{1-n} a^{n-1}+a^{n-1} a^{1-n}\right) \bar{I}_{s}=3 \bar{N}_{s t}^{n} \bar{I}_{s}
$$

where $N_{s t}$ is stator winding coefficient in [9], the backward components of the stator MMF are given as

$$
\bar{J}_{s h}^{u}=3 \bar{N}_{s t}^{u} \bar{I}_{s}
$$

The rotor winding currents set up fundamentally-distributed rotating MMF waves, which can be expressed in stator coordinates so that

$$
j_{R}(y, t)=\operatorname{Re} \sum_{n=-\infty}^{\infty} \bar{J}_{R_{j}} e^{j\left(a t-p_{m}(y)\right.}+\bar{J}_{R_{b}} e^{j\left((2 s-1) a r+p_{m} k y\right)}
$$

where

$$
\begin{aligned}
& \bar{J}_{R_{f}}^{m \prime}=\bar{I}_{R_{1}} \bar{N}_{r}^{m+}+a^{m} \bar{I}_{R_{2}} \bar{N}_{r}^{m}+a^{-m} \bar{I}_{R_{r}} \bar{N}_{r}^{m}
\end{aligned}
$$

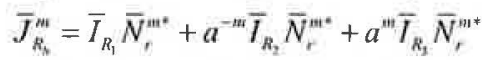

and $N_{r}$ is rotor winding coefficient given in [9]. The torque in (8) includes the state steady and oscillating components developed by the machine. The open circuit (running with noload) and the short circuit (locked rotor) tests were performed to obtain machine parameters. Using these parameters, an impedance matrix was built. The measurement of the torque was taken with the rotor shorted circuited. Fig. 1 presents the measured and predicted values of the torque for healthy machine with neglecting harmonics components. It is close enough to show the validity of the analysis. The referred rotor current for the first phase can be found by (14), and similar expression for $I_{R 2}$, and $I_{R 3}$, where $\operatorname{Tr}$ is the stator-rotor turns ratio given in (15), and $k_{s k}$ is the conventional rotor skew factor [9]:

$$
\begin{gathered}
I_{R_{t}}=-\left(\frac{T r}{k_{s k}}\right) I_{r_{t}} \\
\operatorname{Tr}=\frac{N_{s t}}{N,}
\end{gathered}
$$

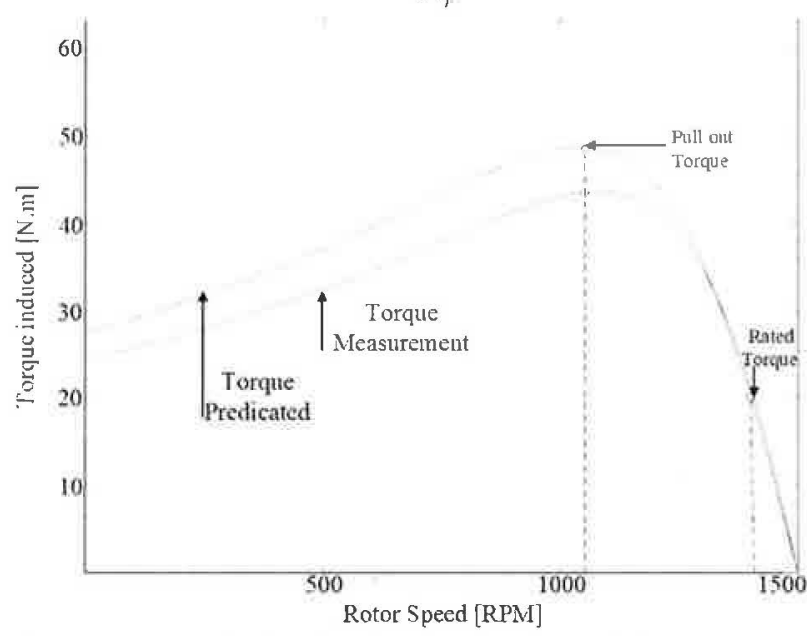

Fig. 1. Experimental and predicted currents versus speed characteristics for balanced rotor.

\section{WOUND ROTOR-EQUIVALENT CIRCUIT}

The currents in the stator and rotor winding are related to the main supply voltage by means of the matrix equation as described early in (1). Hence it symbolizes the complete rotor, before any fault has occurred. The system of $\mathrm{N}$ complex linear equations, where $\mathrm{N}$ is the number of rows in the matrix, can be solved by any convenient means to find the $\mathrm{N}$ unknown currents. The matrix equation defined in (1) assumes that the rotor phases are short-circuited. However, the rotor windings are connected to a network of external impedances, as in (2). Assuming the external impedance is symmetrical about one phase and this phase is connected with $R_{1}$ :

$$
R_{2}=R_{3} \neq R_{1}
$$

The simplified equivalent circuit transformed to primary side, and with the mutual impedance replaced by its equivalent T-network, is shown in Fig. 2. . The resultant equivalent circuit is converted to constant frequency though the system. Using the turns ratio in (15), the rotor components are referred to the stator. Commonly the skew is removed so the skew coefficient will be unity and the skew reactance will disappear. The core 
loss resistance is involved in the circuit. The stator impedance can be written with reference to the forward and backward components. The backward component varies because it is divided by $(2 s-1)$.

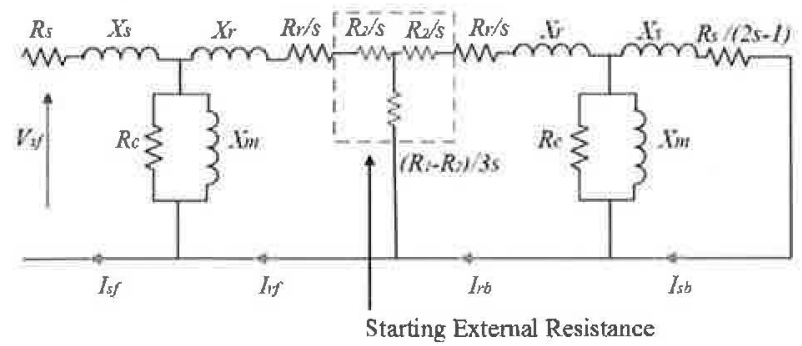

Fig. 2. Simplified equivalent circuit for wound rotor induction machine.

\section{SIMULATION OF WOUND ROTOR FAULTS}

Rotor faults can be simulated through illustrating appropriate relationships between various rotor-currents, and reducing the coupling impedance matrix. For instance, assuming one of the rotor phases is open, the impedance matrix is modified by deleting the row and the column related to that phase, and the corresponding entries in the voltage and current vectors are likewise deleted. If the rotor windings are asymmetrical, then negative-sequence voltages will be generated.

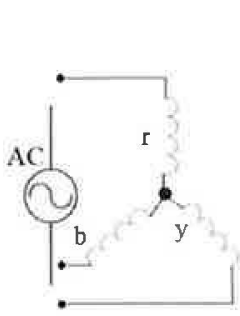

Stator winding

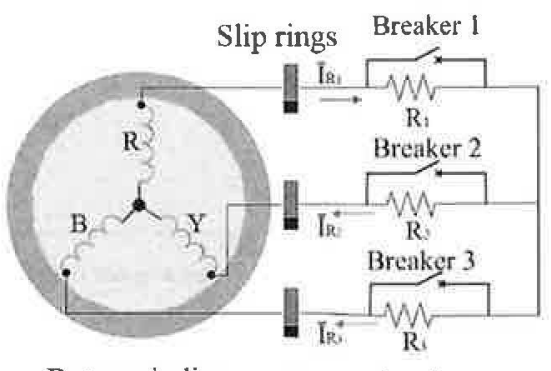

Rotor winding External resistances
Fig. 3. Simulation of wound rotor connected with extemal resistance

A combination of resistors was utilized with two of the phases short-circuited and the remaining phase connected to a small resistor. For instance, phases 1 and 3 are short-circuited and phase 2 is connected to a small resistor (around $2 \Omega$ ). This represents a referred resistance of approximate $25 \Omega$. The rotor phases were then connected to a group of balanced resistors. As shown in Fig. 3, MATLAB Simulink was used to simulate the rotor faults. The series of resistances are connected to the rotor phases and they were controlled by breakers. The matrix was programmed in MATLAB with different sets of external resistors.

Experimental verification of the theory developed in Section 2 is carried out using a three phase, four-pole wound rotor induction machine. The data for this machine are given in Table 1. Fig. 4 presents the torque for a healthy motor, a motor with asymmetrical resistance ( $R_{1}$ and $R_{3}$ short-circuited, and $R_{2}$ $=2 \Omega$, and a healthy motor with symmetrical resistances. Connecting resistances in series with rotor phases increases the starting torque, and also reduces starting current as shown in Figs. 4 and 5. A loss of the steady torque and more oscillation will be introduced by an unbalanced rotor. The losses in the rotor part are increased after adding the external resistance to the rotor, even if the symmetrical resistance is added, as shown in Fig. 6. The rotor resistance could be used to control the speed of the motor but the losses of the system will makes this control method not viable.

TABLE IMACHINE SPECIFICATION

\begin{tabular}{llll}
\hline \multicolumn{4}{c}{ Name plate details } \\
\hline \hline Power [HP] & 10 & Speed [rpm] & 1420 \\
Frequency [Hz] & 50 & Stator voltage [V] & $400 / 440$ Delta \\
Stator rated current [A] & 13 & Rotor Voltage [V] & 200 \\
Rated rotor current [A] & 22 & Slip [p.u.] & 0.0533 \\
\hline \multicolumn{4}{c}{ Measured resistances per phase } \\
\hline \hline R stator (DC, cold) & $1.82 \Omega$ & R rotor (DC, cold) & $0.23 \Omega$ \\
\hline \hline
\end{tabular}

The negative dip in the state steady torque occurs at slip $=$ 0.5 (half speed point) as shown in Fig. 7. It can be illustrated that the main oscillating torque generated by the backward rotor field is at a frequency of $2, s f$, and this oscillating torque would occur if the machine is run at half speed with an unbalanced rotor. The impact of asymmetrical resistors on the three rotor phase currents is shown in Fig. 8. The main variations of three rotor currents reflect the imbalance of the external rotor resistors.

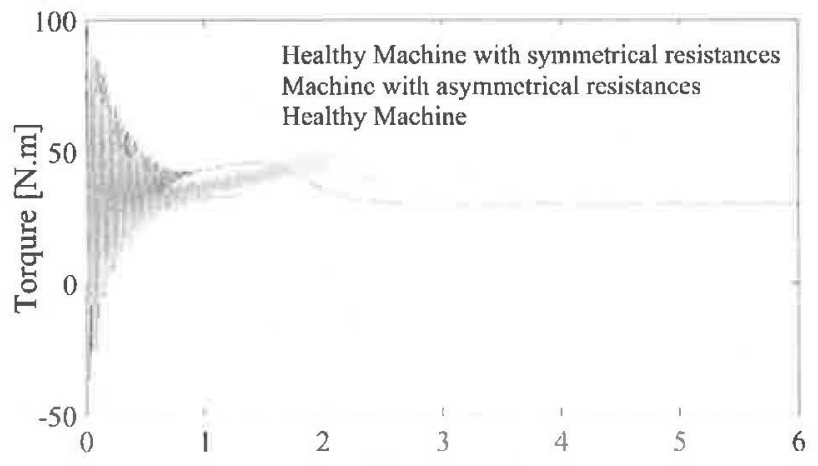

Time $\lceil$ secs $\rceil$

Fig. 4. Electromagnetic torque developed by the machine with rated load.

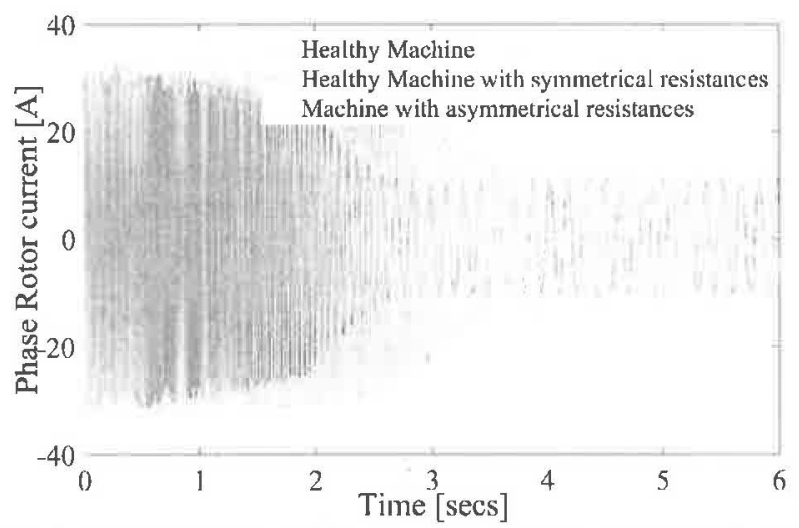

Fig. 5. Simulated rotor currents v.s. time response for balanced and unbalanced rotors. 


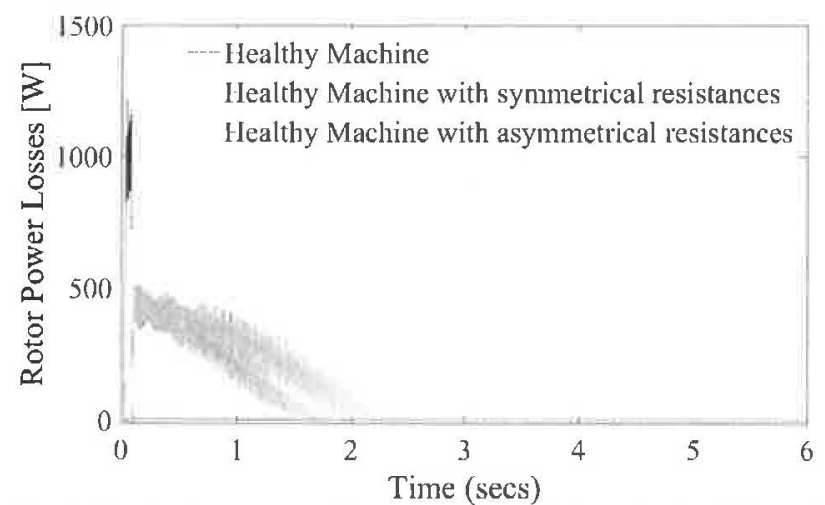

Fig. 6. Simulated rotor power losses $\mathrm{v}_{\mathrm{s}} \mathrm{s}$, time for balanced and unbalanced rotor.

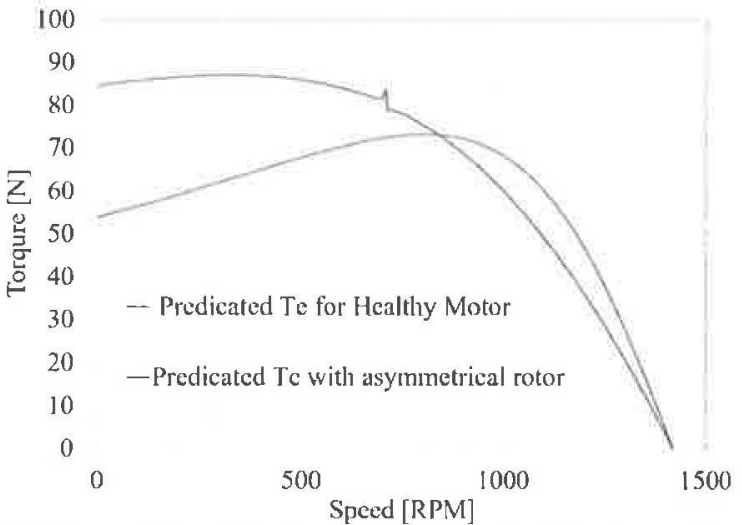

Fig. 7. Characteristics of steady state torque developed by the machine vs. speed

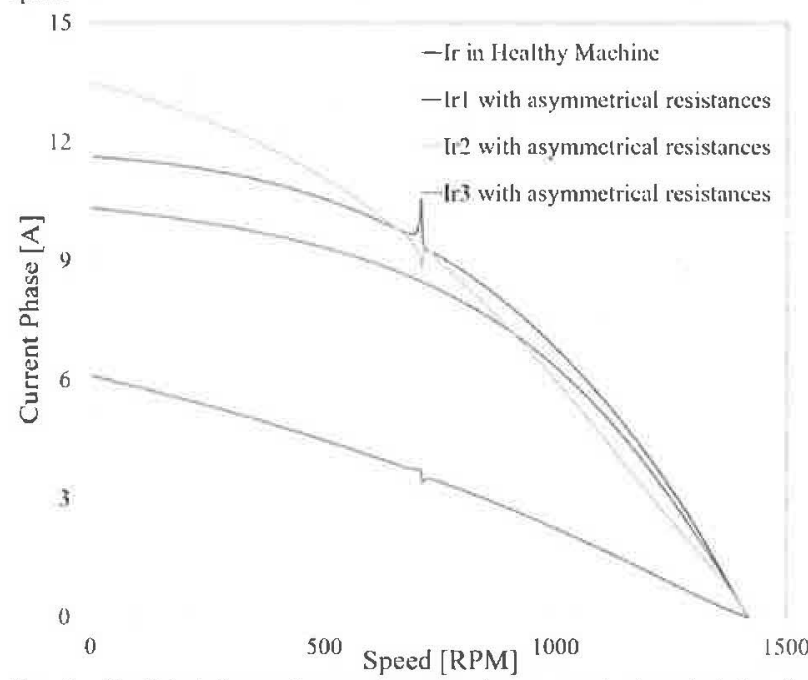

Fig. 8. Predicted three phase rotor currents vs. speed characteristics for balanced and unbalanced rotors.

Fig. 9 shows that $I_{s b}$ rapidly drops to zero at the half speed point. It will occur when the backward field generated by the asymmetrical rotor is stationary with respect to the stator, and it can hence produce no EMFs in the stator coils.

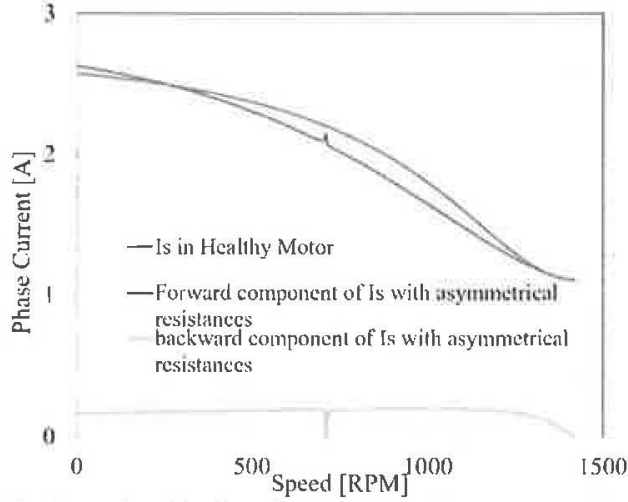

Fig. 9. The forward and backward components of stator current for balanced and unbalanced rotors.

\section{EXPERIMENTAL WORK AND RESULTS}

A four-pole wound rotor induction machine was used as shown in Fig. 10, and the data for the machine were given early in Table 1. The slip rings were connected to three variable resistors (1-5) $\Omega$. Torque transducer was added to continuously measure the speed and torque of the machine. The analysis and measurement indicate that the stator and rotor power losses would increase in the fault condition, which is also shown in Fig. 11. There is a jump in the rotor winding loss in the faults condition during the starting time. The substantial variations in the three phase currents in Fig. 12 result from imbalance of the resistors that are connected to rotor winding.

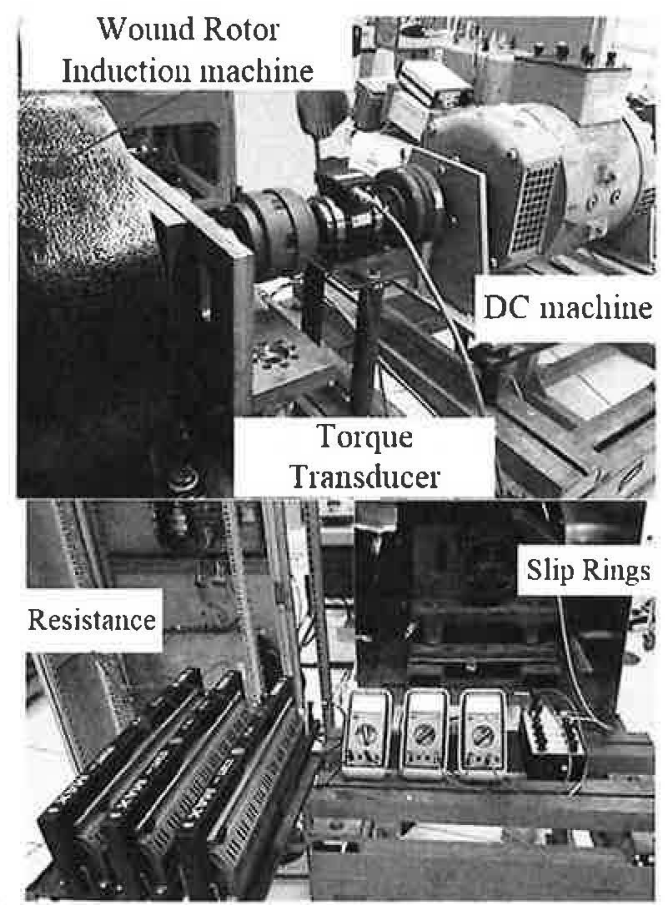

Fig. 10. Experiment with 4 poles wound rotor machine and external resistance (front and side views). 


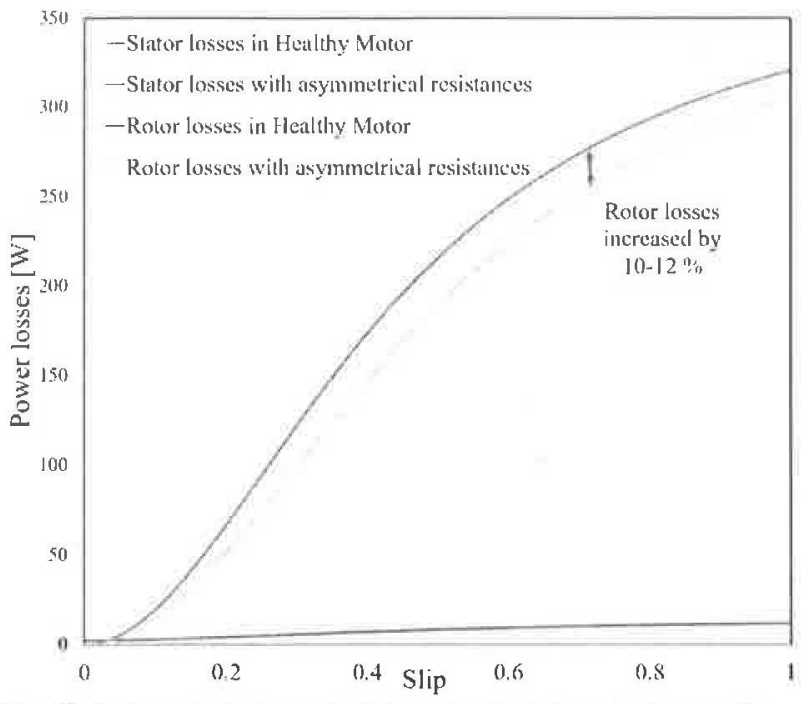

Fig. 11. Stator and rotor losses for balanced and unbalanced rotors vs, slip. is

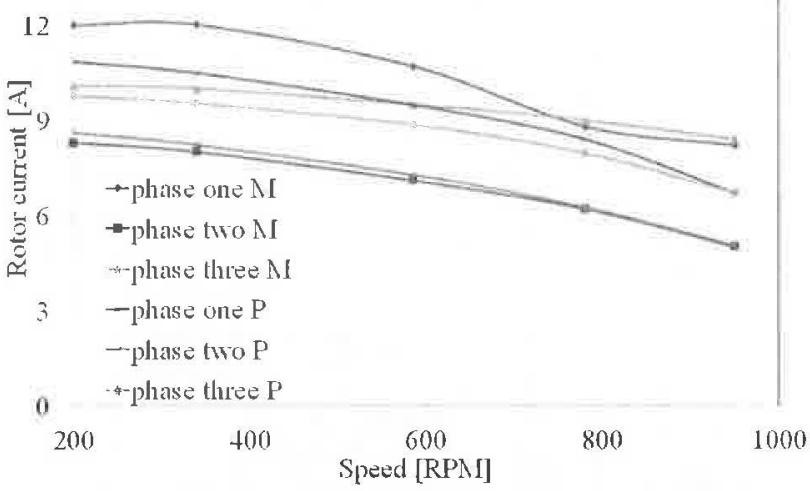

Fig. 12. Measured and predicted rotor phase currents for unbalanced rotor, (letter M refers to measured value, while letter P refers to predicted valuc).

\section{CONCLUSION}

The work presented in this paper has been developed with a powerful and a relatively simple model for testing the behavior of DFIG machines with rotor-wound faults. This model was coded in MATLAB, and different tasks were applied for identifying and examining the cases of unbalanced rotor. It has been illustrated both theoretically and by simulation that rotor faults may be detected by their response to backward sequence stator excitation. Running the induction machine with an unbalanced rotor would introduce a loss of steady torque, and increased oscillating torque. The coupling matrix can be improved to incorporate eccentricity faults and rotor winding or DFIG faults in wound rotor machines. Furthermore, the impedance technique is adaptable and powerful for use as the basis as a condition monitoring system. Future work will focus on using the matrix to study stator and rotor winding harmonics.

\section{ACKNOWLEDGMENT}

The authors would like to sincerely thank Al-Hussein Bin Talal University for their financial support given through doctoral scholarship to the student Ahmad Salah.

\section{REFERENCES}

[1] S. Djurovic, C. J. Crabtree, P. J. Tavner, and A.C. Smith, "Condition monitoring of wind turbine induction generators with rotor electrical asymmetry," IET Renew, Power Gener, vol. 6, no. 4, pp. 207-216, 2012.

[2] B. Lu, Y, Li, X. Wu, and Z. Yang, "A revicw of recent advances in wind turbine condition monitoring and fault diagnosis," IEEE PEMWA conference, Lincoln, NE, USA, June 2009, pp. 1-7.

[3] W. T. Thomson and M. Fenger, "Current signature analysis to detect induction motor faults," IEEE Industly Applications Magasine, vol. 7, no. 4, 2001, pp. 26-34, 2001.

[4] T. Barton and B. Doxey, "The operation of three-phase induction motors with unsymmetrical impedance in the secondary cilcuit," Proceedings of the IEE-Parl A: Power Engineering, vol. 102, pp. 7I-79, 1955.

[5] D. G. Dorrell, W T Thomson, and S. Roach, "Analysis of airgap flux, current and vibration signals as a function of the combination of static and dynamic airgap eccentricity in 3-phase induction motors", IEEE Trans. Ind. Applications, vol, 33, no.1, pp. 24-34, 1997.

[6] G. B. Kliman, R. A. Kocgl, J. Stcin, R. D. Endicott, and M. W. Madden, "Noninvasive detection of broken rotor bars in operating induction motors," IEEE Trans. Energy Convers,, vol. 3, no. 4, pp. 873-879, 1988.

[7] A. M. da Silva, R. J. Povinelli, and N. A. O. Demerdash, "Induction inachine broken bar and stator short-circuit fault diagnostics based on three-phase stator current envelopes," IEEE Trans. Ind Electron, vol. 55 , no. 3, pp. 1310-1318, 2008

[8] D. G, Dorrell, "Calculation of Unbalanced Magnetic Pull in Cage Induction Machines," Thesis, University of Cambridge, 1993.

[9] A. Salah, Y. Guo, and D. Dorrell, "Impedance matrix analysis technique in wound rotor induction machines including general rotor asymmetry," in Proc: 42" Annual conf. of the IEEE Ind. Electronics Society, 2016, pp. $1821-1826$.

[10] A. C. Smith, "Harmonic field analysis for slip-ring motors including general rotor asymmetry," IEEE Trans. Ind. Applications, vol. 26, pp. $857-865,1990$.

[11] D. G. Dorrell, J. K. Shek, M. A. Mueller, and M.F. Hsieh, "Damper windings in induction machines for reduction of unbalanced magnetic pull and bcaring wear," IEEE Trans. Ind. Applications, vol 49, pp. 2206-2216, 2013.

[12] A. Ceban, R. Pusca, and R. Romary, "Study of rotor faults in induction motors using external inagnetic field analysis," IEEE Trans Ind. Electro, vol 59, pp. 2082-2093, 2012.

[13] D. G. Dorrell, "Design requirements for doubly-fed reluctance generators," in Proc $20077^{\text {th }}$ Int Conf. on Power Electronic's and Dive Systems, 2007, pp 981-988.

[14] D. G. Dorrell and $\Lambda$. Salah, "Detection of rotor eccentricity in wound rotor induction machines using pole-specific search coils," IEEE Trans. Magn, vol, 51, article 811604, 2015. 